Article

\title{
What Is the Capacity of Individuals with Schizophrenia and Bipolar Disorder to Make Healthcare Decisions? An Exploratory Study of the Views of Patients, Psychiatrists, and Family Caregivers-A Survey on Decisional Capacity in Mental Health
}

\author{
Enric Vicens Pons ${ }^{1}$, Alfredo Calcedo Barba ${ }^{2, * \mathbb{C}}$, Jacinta Hastings ${ }^{3}$, Miia Männikkö ${ }^{4}$ and Silvia Paz Ruiz ${ }^{5}$ \\ 1 Red de Investigación en Actividades Preventivas y de Promoción de la Salud, Department of Psychiatry, \\ Parc Sanitari Sant Joan de Déu, 08830 Barcelona, Spain; evicens@pssjd.org \\ 2 Department of Psychiatry, Hospital Gregorio Marañón; Medical School, Universidad Complutense de \\ Madrid, 28007 Madrid, Spain \\ 3 Board Member, GAMIAN-Europe, 1050 Troonstaat, Belgium; ceo@bodywhys.ie \\ 4 President, EUFAMI, 3000 Leuven, Belgium; miia.mannikko@hotmail.com \\ 5 SmartWorking4U, 12560 Valencia, Spain; silvia.paz@smartworking4u.com \\ * Correspondence: calcedo@ucm.es; Tel.: +34-91-4265244
}

check for updates

Citation: Vicens Pons, E.; Calcedo Barba, A.; Hastings, J.; Männikkö, M.; Paz Ruiz, S. What Is the Capacity of Individuals with Schizophrenia and Bipolar Disorder to Make Healthcare Decisions? An Exploratory Study of the Views of Patients, Psychiatrists, and Family Caregivers-A Survey on Decisional Capacity in Mental Health Psychiatry Int. 2021, 2, 127-144. https://

doi.org/10.3390/psychiatryint2020010

Academic Editor: Mirko Manchia

Received: 31 January 2021

Accepted: 21 March 2021

Published: 1 April 2021

Publisher's Note: MDPI stays neutral with regard to jurisdictional claims in published maps and institutional affiliations.

Copyright: (c) 2021 by the authors. Licensee MDPI, Basel, Switzerland. This article is an open access article distributed under the terms and conditions of the Creative Commons Attribution (CC BY) license (https:/ / creativecommons.org/licenses/by/ $4.0 /)$.

\begin{abstract}
Background: Research on the decisional capacity of schizophrenia and bipolar disorder patients mostly reflects the hospital context. Aim: To describe the views of patients, psychiatrists, and caregivers on the capacity of individuals with schizophrenia and bipolar disorder to make everyday decisions on their care related to their illness. Methods: A survey was conducted among schizophrenia and bipolar disorder patients, psychiatrists, and caregivers (June 2019 to January 2020; seven countries). A questionnaire was emailed to members of the Global Alliance of Mental Illness of Advocacy Network-Europe (GAMIAN; patients) and the European Federation of Families of People with Mental Illness (EUFAMI; caregivers) and to psychiatrists who voluntarily agreed to participate. Questions referred to patients' involvement and capacity for healthcare decision making, and to barriers to and opportunities for autonomous decision making. Frequency, agreement, and importance were rated on Likert scales. Descriptive statistics were conducted. Results: 21 schizophrenia or bipolar disorder patients (52.3\% female; mean age (years) \pm SD: $50.71 \pm 12.02$ ), 11 psychiatrists ( $18.2 \%$ female), and 15 caregivers ( $86.6 \%$ female; $100 \%$ family related) participated in the survey. In total, $86 \%$ of patients felt frequently involved in decisions about everyday care and medications, and $91 \%$ of psychiatrists and $40 \%$ of caregivers perceived the same; $38 \%$ of patients felt frequently involved in decisions about the use of acute symptom medications, and $57 \%$ on care planning, and $55 \%$ and $82 \%$ of psychiatrists, and $40 \%$ and $53 \%$ of caregivers, respectively, believed the same; and $86 \%$ of patients, $91 \%$ of psychiatrists, and $47 \%$ of caregivers agreed on the capacity of schizophrenia or bipolar disorder patients to value the implications of taking medicines to prevent acute psychotic crises. Poor understanding and training are barriers, while advocacy and increasing interest in patients' needs are opportunities for increasing autonomous decision making. Conclusions: Stakeholders concur that schizophrenia and bipolar disorder patients have the capacity to make everyday decisions around their care related to their illness, including acute symptom management. Barriers and opportunities exist to foster autonomous decisions among mental illness individuals.
\end{abstract}

Keywords: schizophrenia; bipolar disorder; decision making; decisional capacity; healthcare; survey

\section{Introduction}

Decision making is the cognitive process that results in the selection of an option among several other possibilities, and it is central in healthcare [1]. Some individuals with serious mental illnesses exhibit decreased decision-making capacity, which limits their 
ability to independently and meaningfully take social, medical, and financial decisions [2] This is particularly challenging for schizophrenia and bipolar disorder patients, where impaired insight and cognitive performance may further decrease their decision-making capacity $[3,4]$. In consequence, their decision-making capacity varies over time and with the type of decision to be made [3,5]. Several studies reveal that schizophrenia and bipolar disorder patients retain the capacity to make treatment and other healthcare-related decisions despite impairments at some stages of the illness, and this can be fully recovered after treatment [6]. Supporting mental illness patients' decisional capacity is crucial as it leads to improved health outcomes and patients' health-related quality of life [7-9].

A patient-centered approach to healthcare and decision making has a significant and favorable impact on patients' satisfaction, treatment adherence, and outcomes in both schizophrenia and bipolar disorder individuals, but also in other mental and non-mental health conditions [10]. Although a great amount of discussion and negotiation occurs between patients and physicians around medications for schizophrenia or bipolar disorder, healthcare providers' decisions tend to dominate the patient-physician relationship, which indicates that there is still room for improvement in the area of patient empowerment [11,12].

Much of the research done so far about decision making capacity in schizophrenia and bipolar disorder has been conducted in hospital settings, around compulsory admissions and treatment, but there is a knowledge gap in the community setting and in the capacity to make everyday life healthcare decisions [13]. Younas et al. (2016) noted that one of the barriers to overcome regarding decision making about antipsychotic medication in individuals diagnosed with serious mental illnesses is patients' insight about their capacity to make decisions [14]. The aim of this study was to explore the views of patients, psychiatrists, and family caregivers about the capacity of individuals with schizophrenia or bipolar disorder to make sound decisions about their healthcare and pharmacological treatments for their psychiatric illness. Having a better understanding of their perceptions is an important step toward improving the chances for an active involvement of patients in healthcare and treatment decisions.

\section{Methods}

\subsection{Design of Study}

This was an exploratory, descriptive, observational, cross-sectional study based on a survey conducted among schizophrenia and bipolar disorder patients, psychiatrists, and family caregivers between 1st June 2019 and 31st January 2020.

Two psychiatrists with expertise in assessing decisional capacity in patients with severe mental disorders and two representatives of the Global Alliance of Mental Illness of Advocacy Network-Europe (GAMIAN) and European Federation of Families of People with Mental Illness (EUFAMI), respectively, formed a study advisory board. This was created to guide the development of the study.

GAMIAN is a patient-driven pan-European organization, representing and advocating the interests and rights of persons affected by mental ill health [15]. Its main activities relate to advocacy, information, awareness raising and education, and partnership and capacity building. EUFAMI is an international non-profit organization with an ongoing commitment to improving care and welfare for individuals affected by mental ill health [16].

\subsection{Selection of Participants}

Schizophrenia and bipolar disorder patients and informal caregivers were active members of GAMIAN and EUFAMI, respectively. They were identified, approached, and invited to take part in the survey by GAMIAN and EUFAMI representatives.

Psychiatrists were identified through a random list of recognized experts on the care of schizophrenia and bipolar disorder patients with a proven professional trajectory longer than 5 years. Citation index and regular co-authorship of publications appeared in mental health journals served to acknowledge expertise in the subject. 


\subsection{Questionnaire}

A semi-structured questionnaire was developed based on an extensive review of the literature, tested, and endorsed by the study advisory board (Figure 1). The study advisory revised and agreed by consensus on the final set of questions and answer options of the questionnaire at a review meeting.
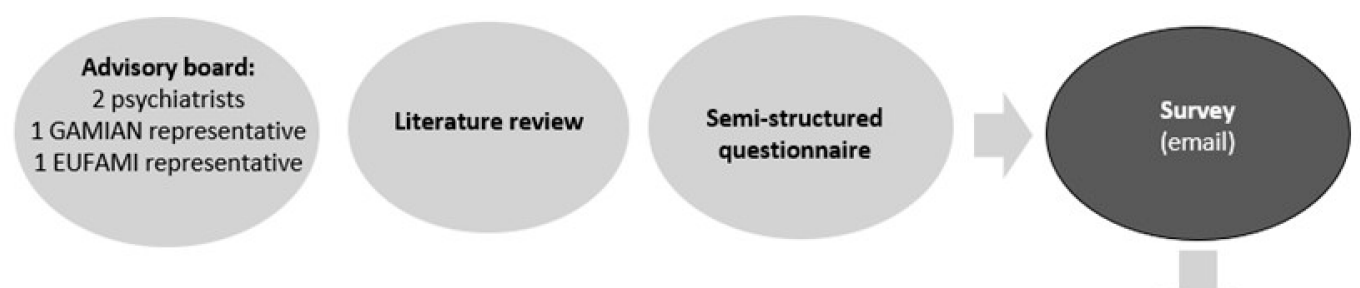

GAMIAN: Global Alliance of Mental Illness Advocacy Networks EUFAMI: European Federation of Families of People Affected by Mental III Health
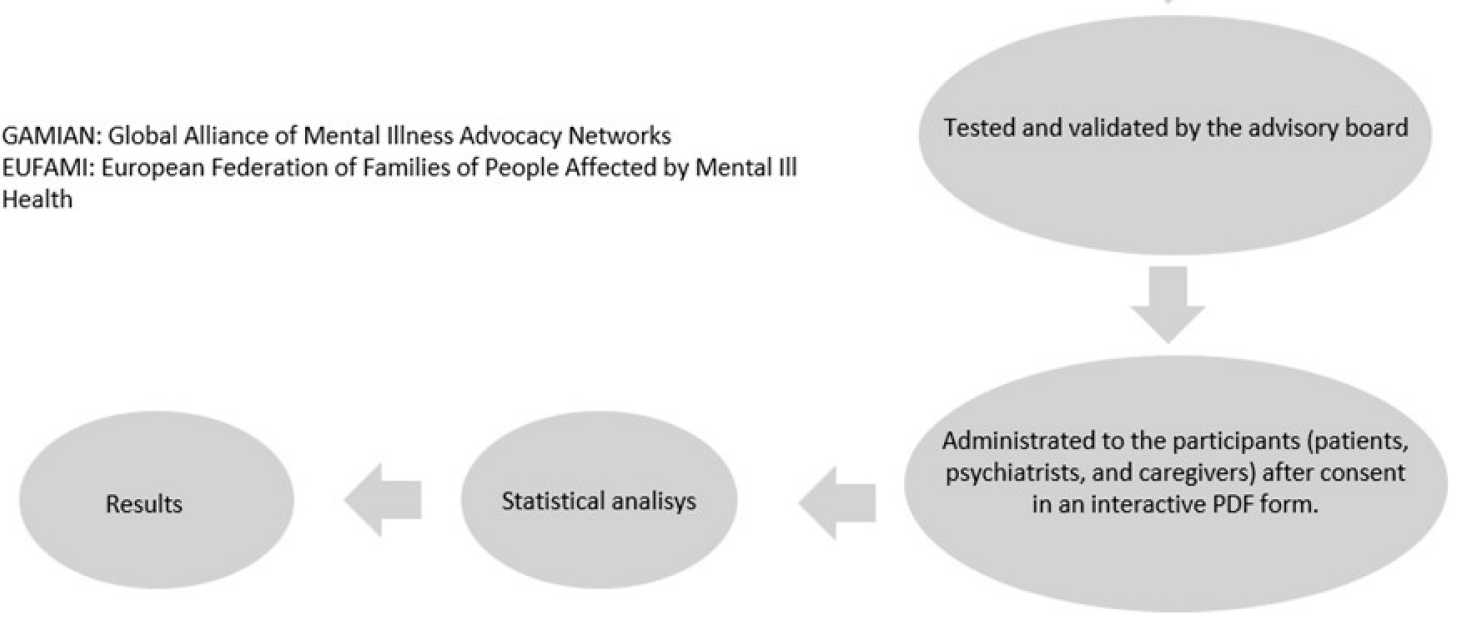

Figure 1. Diagram of research methods.

The questionnaire was written in English and included closed-ended questions. A first set of questions referred to sociodemographic data and on information about their disease (patients), about the patients they treated (psychiatrists), or the patient they cared for (caregivers).

A second set of questions assessed the participants' frequency of involvement in decisions and discussions about overall healthcare, regular medications, medications for acute symptoms, hospital admissions, and advance directives and care planning. Patients were asked about their perception of self-involvement, while psychiatrists and family caregivers were asked about their perceived involvement of schizophrenia and bipolar disorder patients.

A third group of questions explored the level of agreement of participants about the capacity of schizophrenia and bipolar disorder individuals to make decisions and to discuss pharmacological treatments, recognize symptoms, take medicines, and evaluate implications of therapy.

Lastly, a fourth set of questions appraised the level of importance that participants granted to barriers and opportunities for autonomous treatment decision making of individuals with schizophrenia or bipolar disorder.

Frequency, level of agreement. and level of importance were rated on a 4- and 5-point Likert scale (from always/totally agree/most important to never/totally disagree/not important at all). In order to minimize a potential social desirability bias, respondents were asked to make a definitive choice and to express both the direction and the strength of their views on the rating scale [17]. 


\subsection{Survey and Data Processing}

A study information sheet and a letter of invitation were emailed to potential candidates to take part. Observing recognized ethical standards, details on the purpose of the survey, on data processing and anonymization, and on the communication of results were provided in the study information sheet [18]. Three reminders were sent to the candidates initially approached. GAMIAN and EUFAMI sent the invitations and information sheets and distributed and collected the questionnaires among patients and family carers who voluntarily agreed to take part. The questionnaire was emailed, and it was self-administered. Questionnaires were assigned an alphanumerical code to dissociate responses from any personal data that could be linked to the respondent. The survey was open for six months. The final sample size was determined by the number of participants who willingly answered the questionnaire.

A database was created to process and analyze responses. Descriptive statistics were conducted. The number and percentage of participants selecting each response category for each statement were calculated and reported.

\section{Results}

A total of 47 invited stakeholders agreed to participate and answered the questionnaire: 21 patients, 11 psychiatrists, and 15 caregivers. Most patients (52.38\% female; age (mean): 50.71 ( \pm SD:12.02) years) had university $(66.67 \%)$ or tertiary $(23.81 \%)$ level education, were on permanent sick leave (33.33\%), were employed part-time (19.05\%) or retired $(14.29 \%)$, and had a diagnosis of either bipolar disorder $(61.90 \%)$ or schizophrenia $(33.33 \%)$ for more than ten years (mean: 15.33 ( \pm 9.53 ) years). Most psychiatrists (81.80\% male; age: $54( \pm 7)$ years) cared for schizophrenia and bipolar disorder patients for more than 10 years (mean: 25 ( \pm 7.43$)$ years). Caregivers $(86.66 \%$ female; age: $66.64( \pm 12.02)$ years) were all a family member of the patient (53.33\% parent; $20 \%$ sibling), had university $(46.66 \%$ ) and doctoral $(26.66 \%)$ level education, and cared for either schizophrenia $(86.66 \%)$ or bipolar disorder $(6.67 \%)$ patients for more than ten years $(26( \pm 11.25)$ years). The mental illness was the main reason for the care provided in most cases $(93.33 \%)$.

A third of patients (33.33\%) resided in Belgium, and the rest in different European countries, including the Czech Republic (4.76\%), France (14.29\%), Hungary $(14.29 \%)$, the Netherlands (9.52\%), Portugal (19.05\%), and Sweden (4.76\%). Psychiatrists were based in different countries across the world: Spain was more represented $(27.20 \%)$, while other participants were equally distributed $(9.10 \%)$ across Australia, Austria, France, Germany, Italy, Mexico, Switzerland, and the United States. Caregivers were mostly based in Austria (26.66\%), Belgium, Malta, and Portugal (13.33\%), followed by other European countries such as Bulgaria, Finland, the Netherlands, and the United Kingdom (6.67\%).

\subsection{Participants' Perceptions of Schizophrenia or Bipolar Disorder Patients' Involvement in Everyday Life Healthcare Decisions}

Based on their experience, $86 \%$ of patients felt that they are always or very frequently involved in decisions about their overall healthcare and the medications for their illness they receive; $71 \%$ felt the same applies to their participation in discussions about hospital admissions. Likewise, $91 \%$ of psychiatrists considered they always or very frequently involve patients with schizophrenia or bipolar disorder in decisions about their overall healthcare; $73 \%$ of them considered they always or very frequently implicate patients in decisions about their medications or in discussions about hospital admissions. Only 40\% of family caregivers viewed that the person with schizophrenia or bipolar disorder they care for is always or very frequently involved in decisions about their overall healthcare and in discussions about hospital admissions, while $47 \%$ considered that involvement in decisions concerning the medications they receive happens very frequently. In total, $20 \%$ of family caregivers believed the person they care for is never involved in decisions about medications for their psychiatric illness (Figure 2). 
a. Percentage of participants rating the frequency of patients' involvement in decisions about their overall healthcare

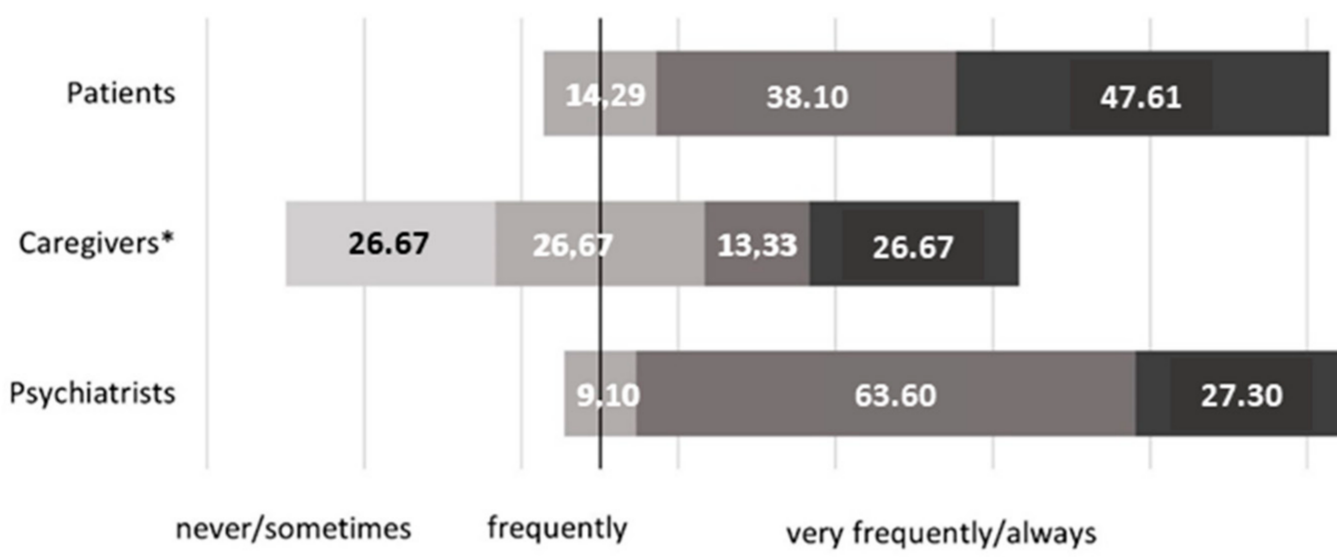

${ }^{*} \mathrm{~N} / \mathrm{A}($ not answered $)=6.66 \%$

mometimes $\quad$ Erequently $\quad$ Very frequently $\quad$ Always

b. Percentage of participants rating the frequency of patients' involvement in decisions about the medication they receive regularly

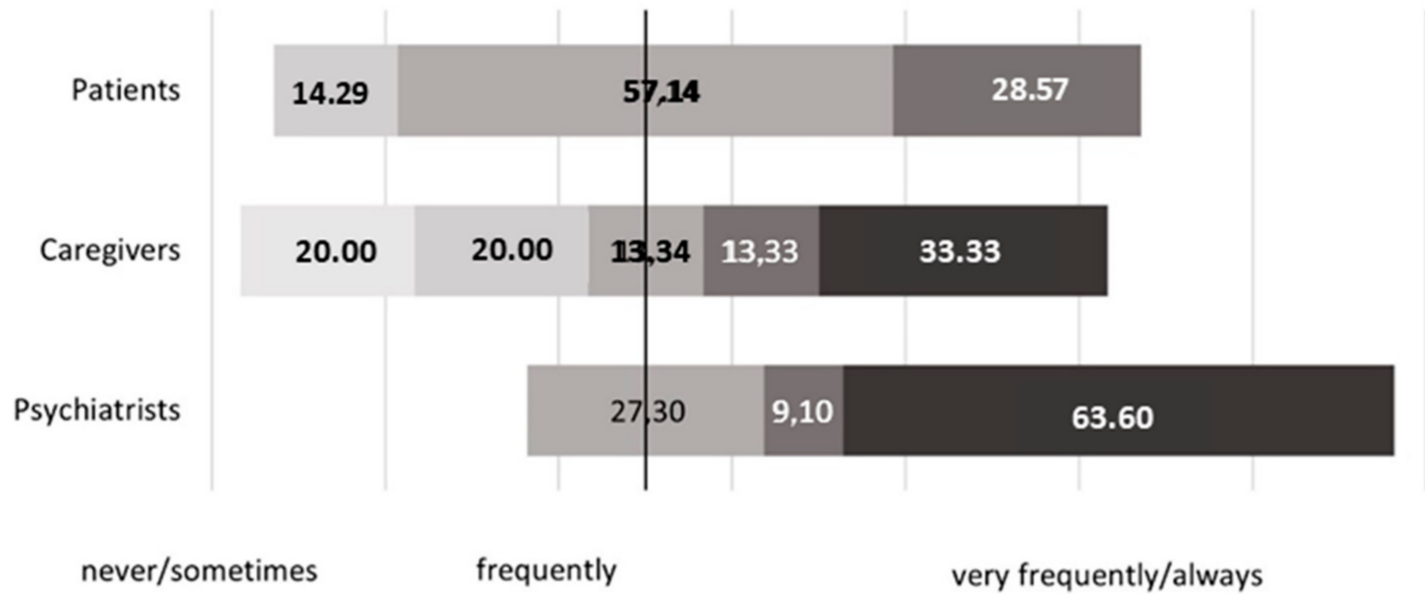

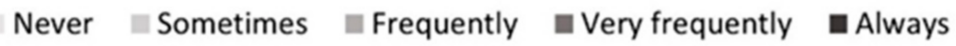

Figure 2. Cont. 


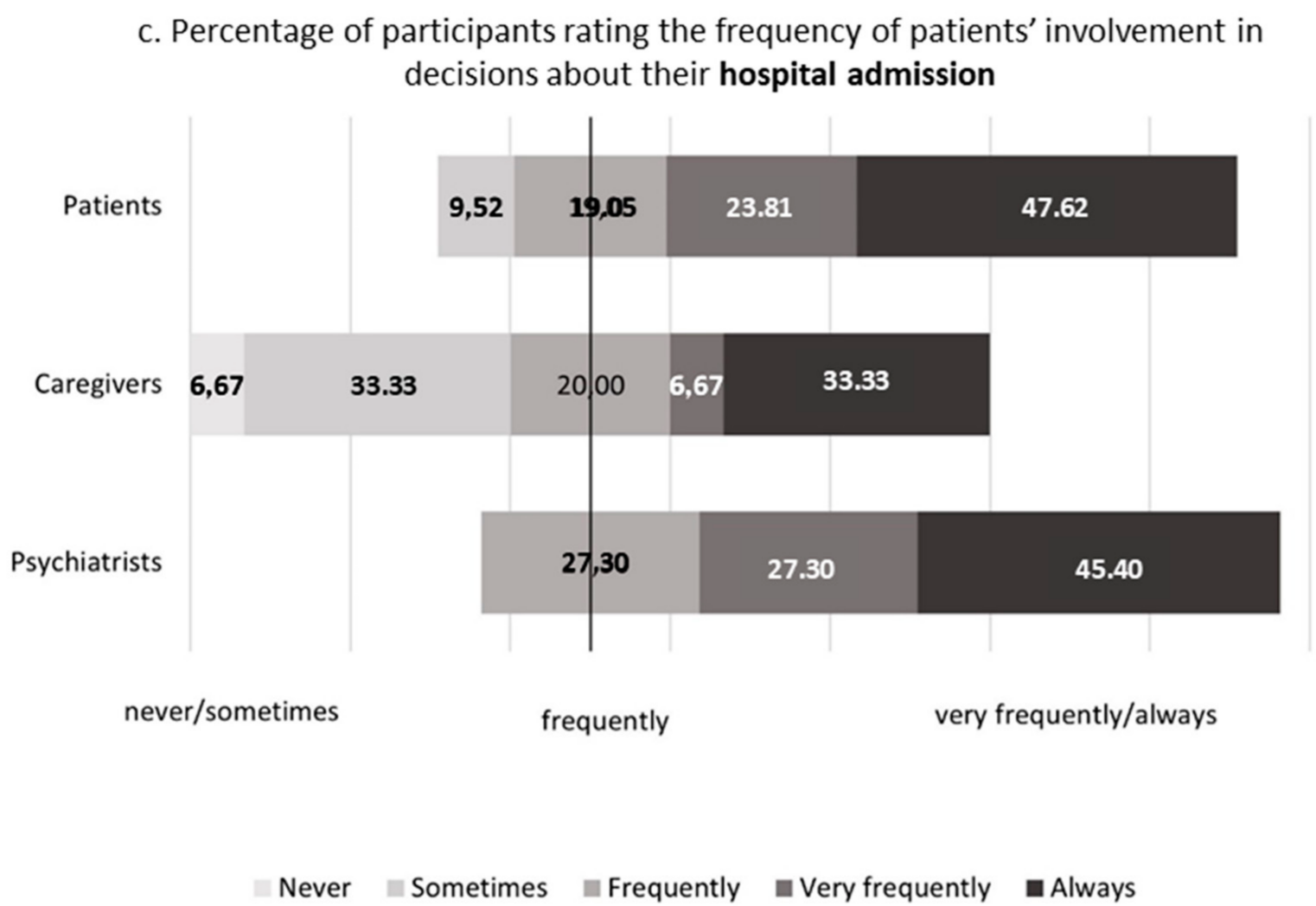

Figure 2. Participants' perception of patients with schizophrenia or bipolar disorder involvement in decisions about (a) overall healthcare, (b) regular medication, and (c) hospital admissions.

3.2. Participants' Perceptions of Schizophrenia or Bipolar Disorder Patients' Involvement in Decisions about Managing Acute Crises and Care Planning

In total, $38 \%$ and $57 \%$ of patients, respectively, felt always or very frequently involved in decisions about the use of medications to control the acute symptoms of a crisis and on crisis plan decisions. Similarly, $40 \%$ and 53\% of family caregivers believed patients are always or very frequently involved in acute symptom medications and care plan (advance directives) discussions. A total of $14 \%$ of patients and $6 \%$ of caregivers thought that patients are never involved in discussions about the management of the crisis in the future.

In total, $55 \%$ and $82 \%$ of psychiatrists, respectively, considered they always or very frequently involve schizophrenia or bipolar disorder patients in decisions about the use of medications for managing crises, and on care planning (Figure 3).

\subsection{Participants' Agreement on Schizophrenia or Bipolar Disorder Patients' Capacity for Discussing and Following Their Psychiatric Treatment}

All surveyed psychiatrists (100\%) totally agreed or agreed with nuances on the capacity of schizophrenia or bipolar disorder patients to discuss the risks (potential adverse events) and benefits (potential health gains) of medications with their clinicians. In total, $86 \%$ of patients and $67 \%$ of caregivers had a similar level of agreement with this statement.

Likewise, most psychiatrists (91\%) and a higher percentage of patients (86\%) compared with family caregivers (47\%) strongly agreed on the capacity of schizophrenia or bipolar disorder patients to take medicines regularly (Figure 4). 
a. Percentage of participants rating the frequency of patients' involvement in decisions about the medication to be used to manage acute crises

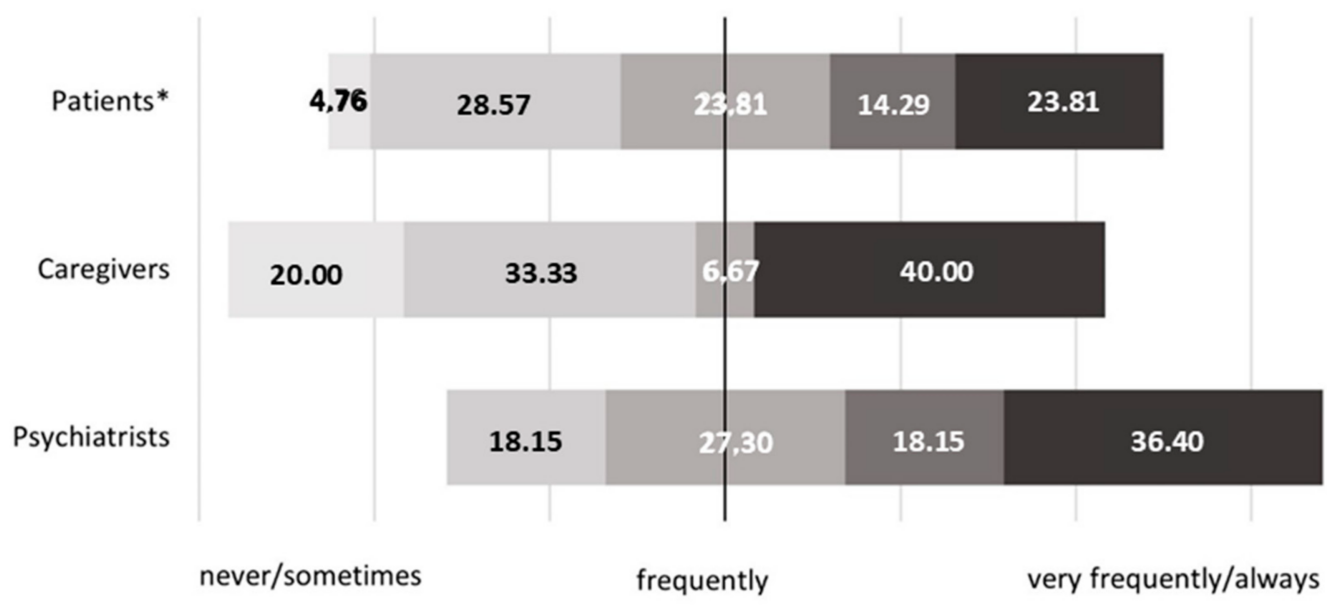

${ }^{*} \mathrm{~N} / \mathrm{A}($ not answered $)=4.76 \%$

Never Sometimes $\square$ Frequently $\square$ Veryfrequently always

b. Percentage of participants rating the frequency of patients' involvement in care planning decisions

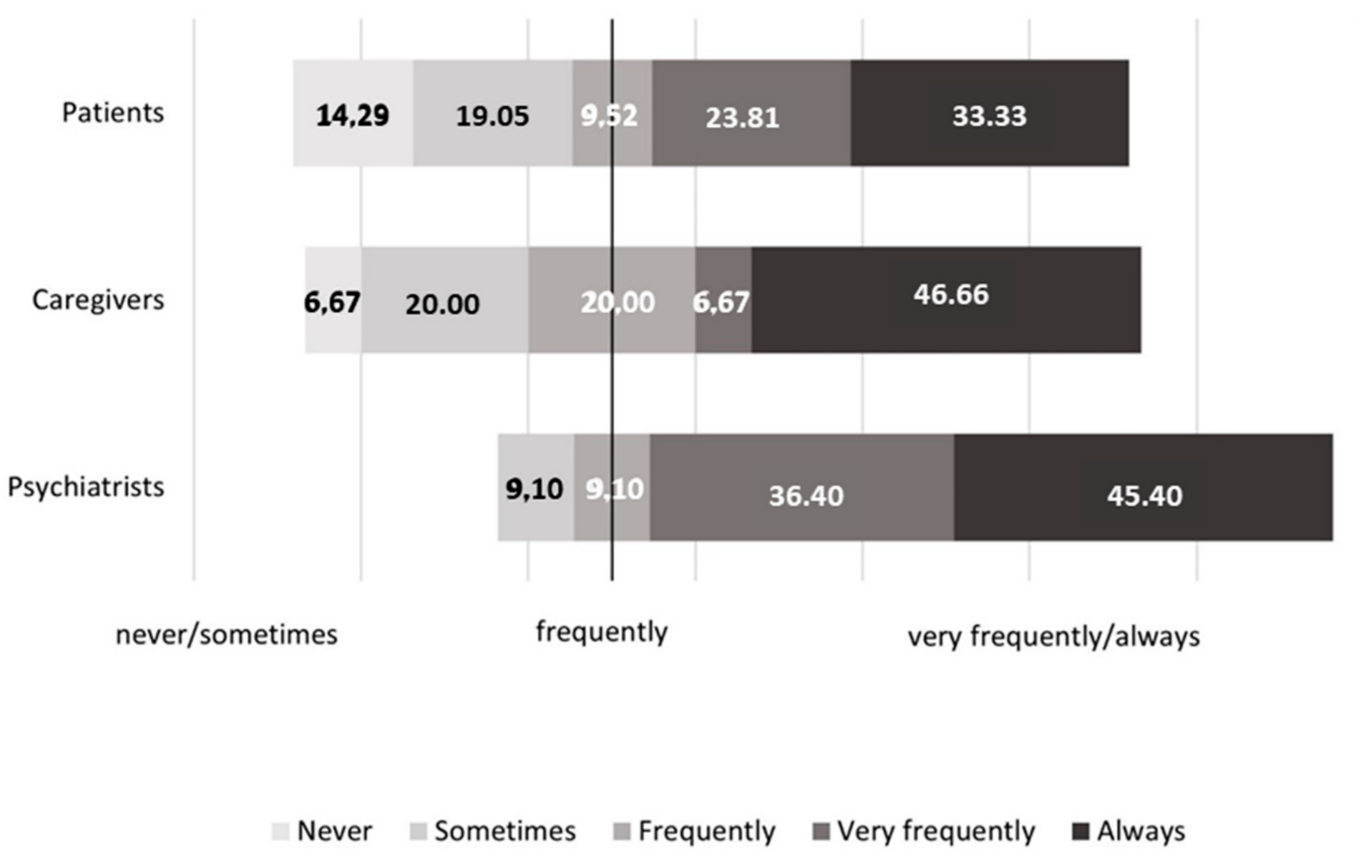

Figure 3. Participants' perception of patients with schizophrenia or bipolar disorder frequency of involvement in decisions about (a) managing acute crises and (b) care planning. 


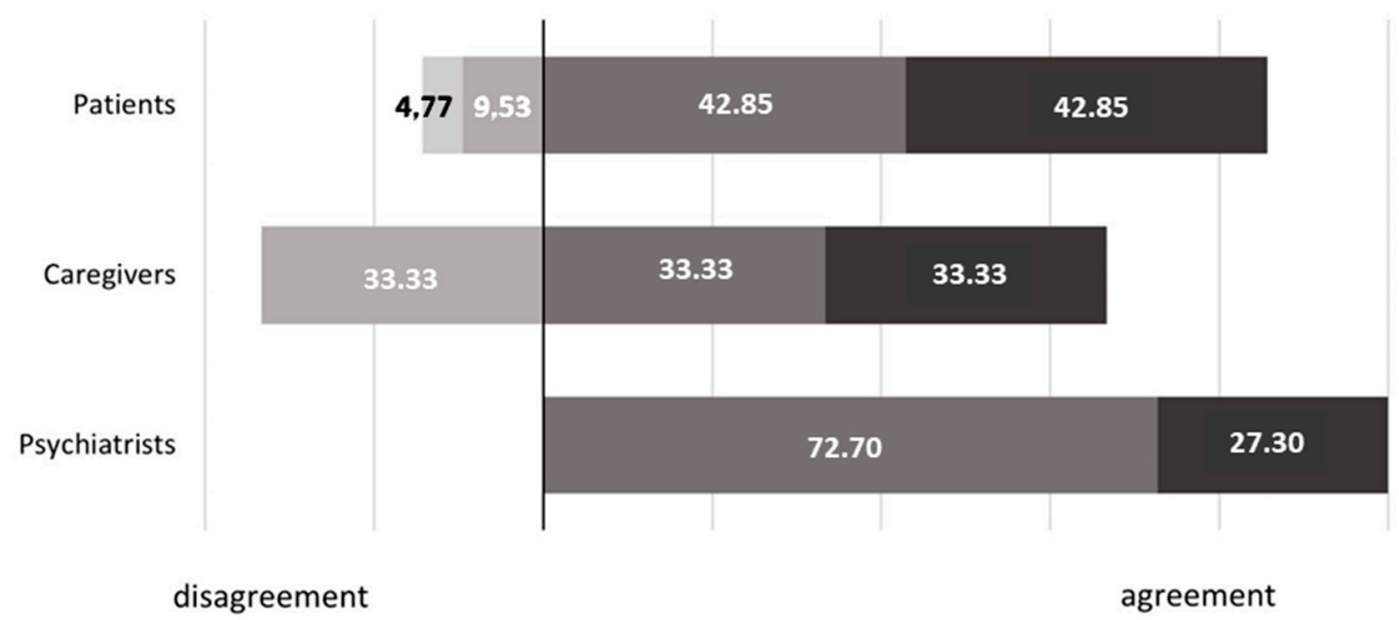

Totally Disagree $\quad$ Partialy disagree $\quad$ Agree with nuances $\quad$ Totally agree

b. Percentage of participants rating their agreement with the patients' capacity to take medicines regularly

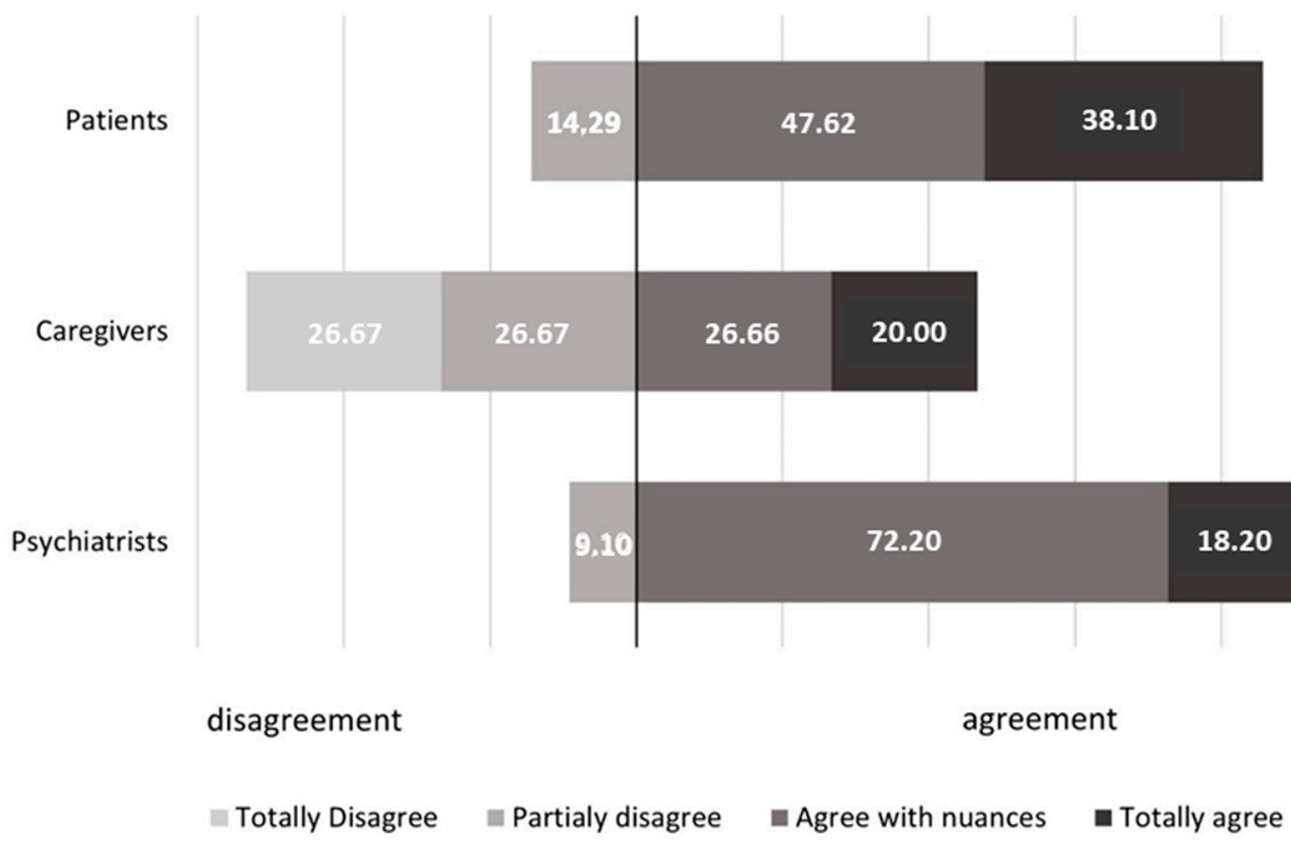

Figure 4. Participants' level of agreement with the capacity of patients with schizophrenia or bipolar disorder to make decisions related to their psychiatric treatment: (a) risk and benefits and (b) taken medicines regularly.

More patients (62\%) and psychiatrists (73\%) than family caregivers ( $40 \%$ ) agreed on patients with schizophrenia or bipolar disorder having the capacity to make decisions about their medical treatment as other non-psychiatric patients with other non-psychiatric clinical conditions. 
3.4. Participants' Agreement with the Capacity of Schizophrenia or Bipolar Disorder Patients to Make and Execute Decisions Related to the Management of Acute Psychiatric Events

Most patients totally agreed or agreed with nuances that schizophrenia or bipolar disorder individuals have the capacity to recognize that they are suffering acute psychiatric symptoms, such as agitation $(81 \%)$, to choose in advance the most advisable treatment option to manage an acute event $(86 \%)$ and to take the right medicine on time to prevent a psychotic crisis (71\%). They were also found to believe that patients can recognize other acute non-psychiatric symptoms of a non-psychiatric condition and to undertake the right action to prevent an acute event, such as a hypoglycemic episode of diabetes mellitus (71\%).

Similarly, $82 \%$ of psychiatrists agreed or agreed with nuances that schizophrenia or bipolar disorder individuals have the capacity to recognize that they are suffering acute psychiatric symptoms as well as non-psychiatric symptoms related to a non-psychiatric condition, and to choose in advance a desirable treatment option to manage an acute event; $72 \%$ strongly agreed on patients having the capacity to take the right medicine on time to prevent a psychotic crisis.

Between $40 \%$ and $60 \%$ of caregivers strongly agreed on the same capacities of schizophrenia or bipolar disorder patients, being more frequently in agreement with their capacity to choose an advisable crisis treatment compared with their confidence on patients' capacity to take the right medicine on time to prevent a psychotic crisis, or to recognize non-psychotic acute symptoms (Figure 5).

\section{a. Percentage of participants rating their agreement with the patients' capacity to recognise acute psychiatric symptoms}

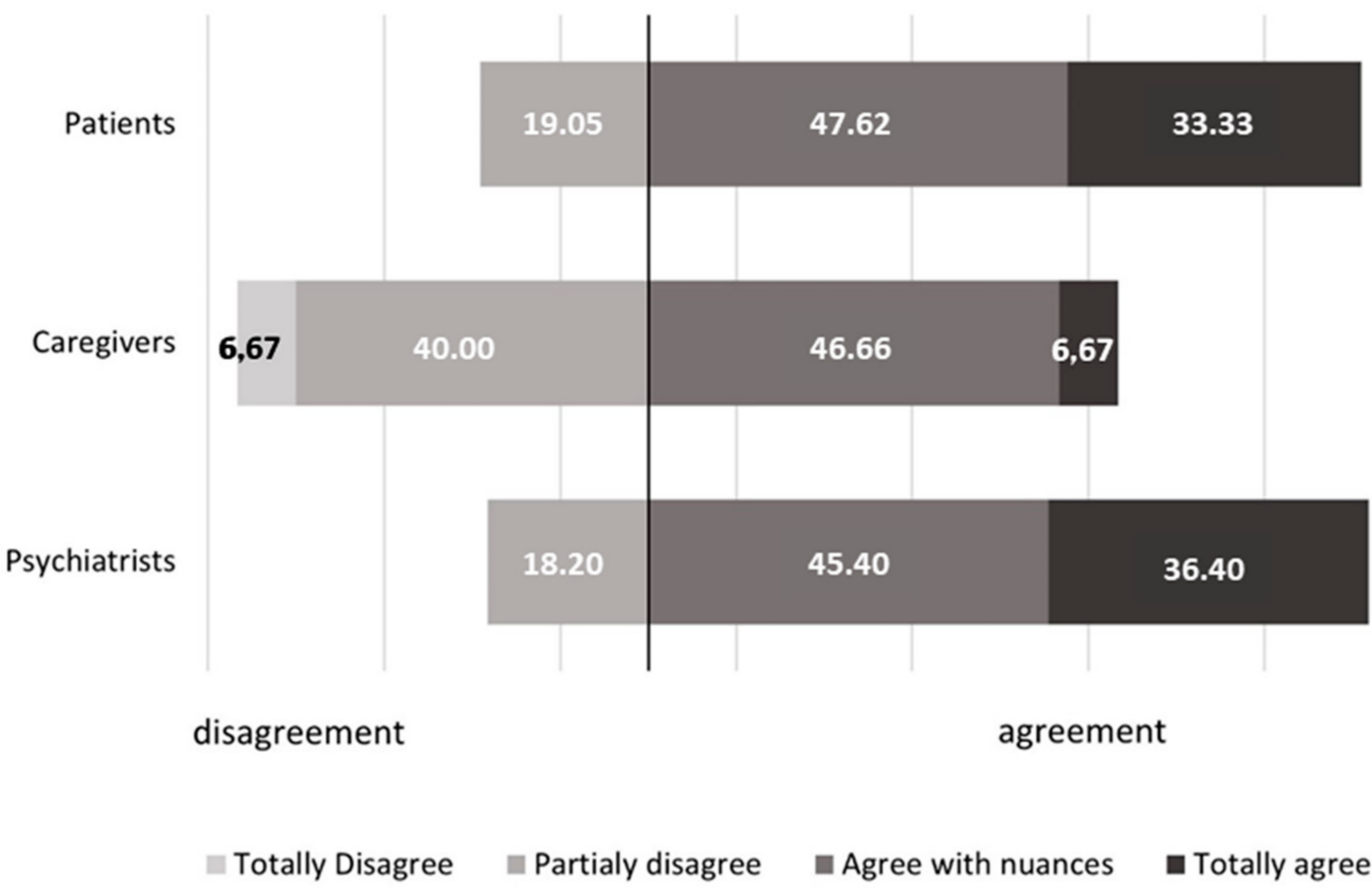

Figure 5. Cont. 
b. Percentage of participants rating their agreement with the patients' capacity to recognise non-psychiatric acute symptoms

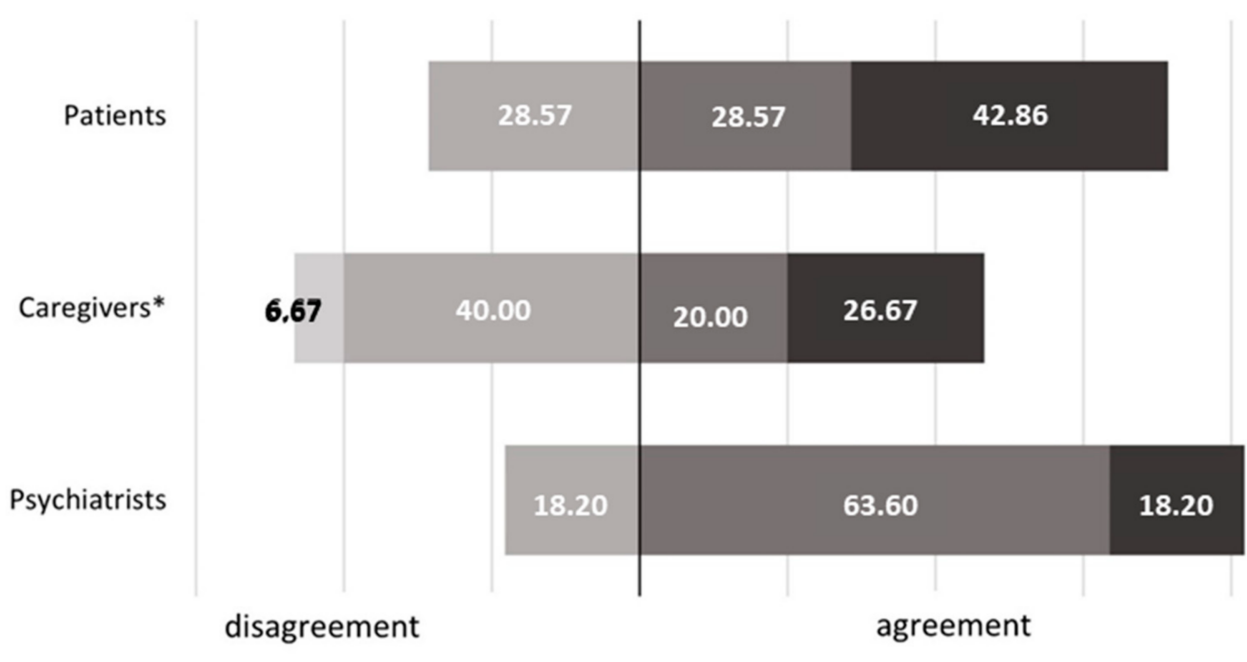

${ }^{*} \mathrm{~N} / \mathrm{A}($ not answered $)=6.66 \%$

घotally Disagree $\quad$ Partialy disagree $\quad$ Agree with nuances $\quad$ Totally agree

c. Percentage of participants rating their agreement with the patients' capacity to choose treatment for an acute psychotic event

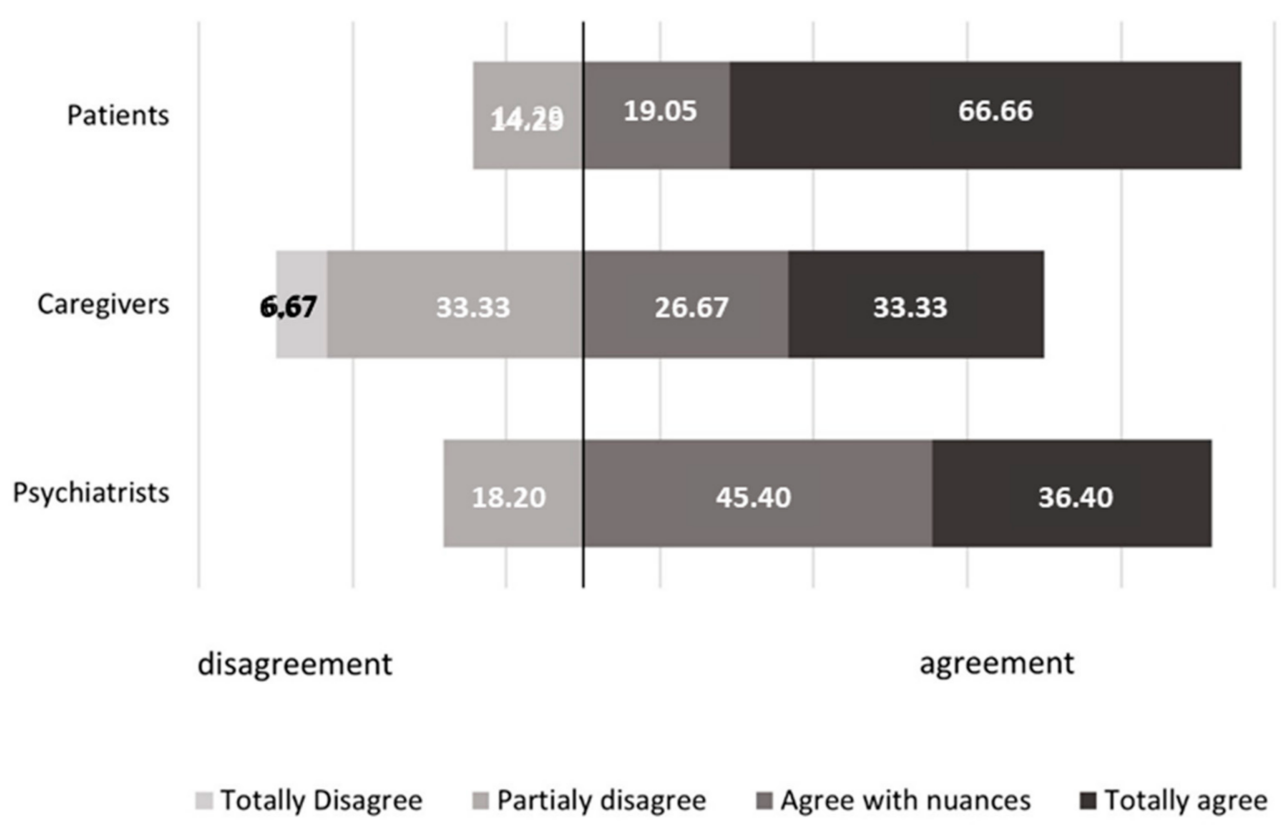

Figure 5. Cont. 


\section{d. Percentage of participants rating their agreement with the patients' capacity to take a medicine on time to prevent a crisis}

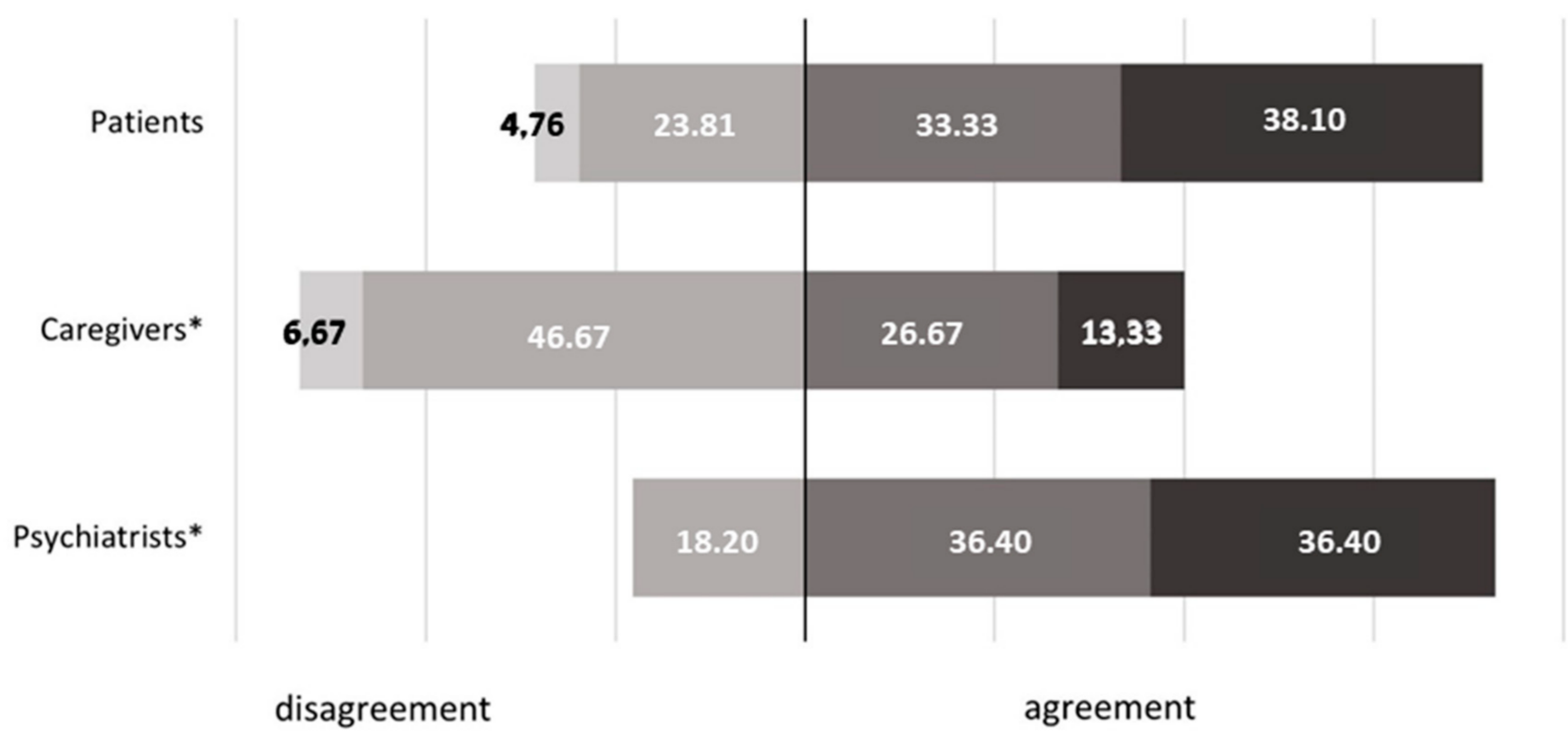

${ }^{*} \mathrm{~N} / \mathrm{A}($ not answered $)=6.66 \%$ of caregivers; $9.00 \%$ of patients

Totally Disagree $\quad$ Partialy disagree $\quad$ Agree with nuances $\quad$ Totally agree

Figure 5. Participants' agreement with the capacity of patients with schizophrenia or bipolar disorder to make and execute crisis-related therapy decisions: (a) recognize acute psychiatric and (b) non-psychiatric symptoms, (c) choose treatment, (d) take medicine on time.

3.5. Participants' Perception of Barriers and Opportunities for Empowering Schizophrenia and Bipolar Disorder Patients to Autonomous Decision Making

Some of the barriers for improving autonomy in making decisions related to their illness in individuals with schizophrenia or bipolar disorder nominated by the participants as most or very important were a poor psychiatrist-patient relationship; a prevailing belief in the restrain and sedate strategy as optimal to control patients' agitation; a predominant paternalistic culture in the healthcare system; poor understanding of autonomous decision making by healthcare professionals; patients' and family caregivers' autonomous decision-making capacity concerns; lack of support, training, and education for healthcare professionals and family caregivers about autonomous decision making in patients with a mental illness; and society's and health policy makers' stigma about schizophrenia or bipolar disorder individuals' capacity to make rational decisions about their healthcare (Figure 6).

Participants also rated many initiatives such as patient and caregiver advocacy, tools and methods developed to support healthcare professionals in the assessment of patients' decision-making capacity, changing culture toward patient-led care, increasing interest in the medical community and society in knowing about the illness experience of individuals suffering from schizophrenia or bipolar disorder, and rising patients' involvement in care plans and treatment choices as the most or very important opportunities to empower autonomy in making decisions among schizophrenia or bipolar disorder individuals (Figure 7). 
Patients Phychiatrists Caregivers

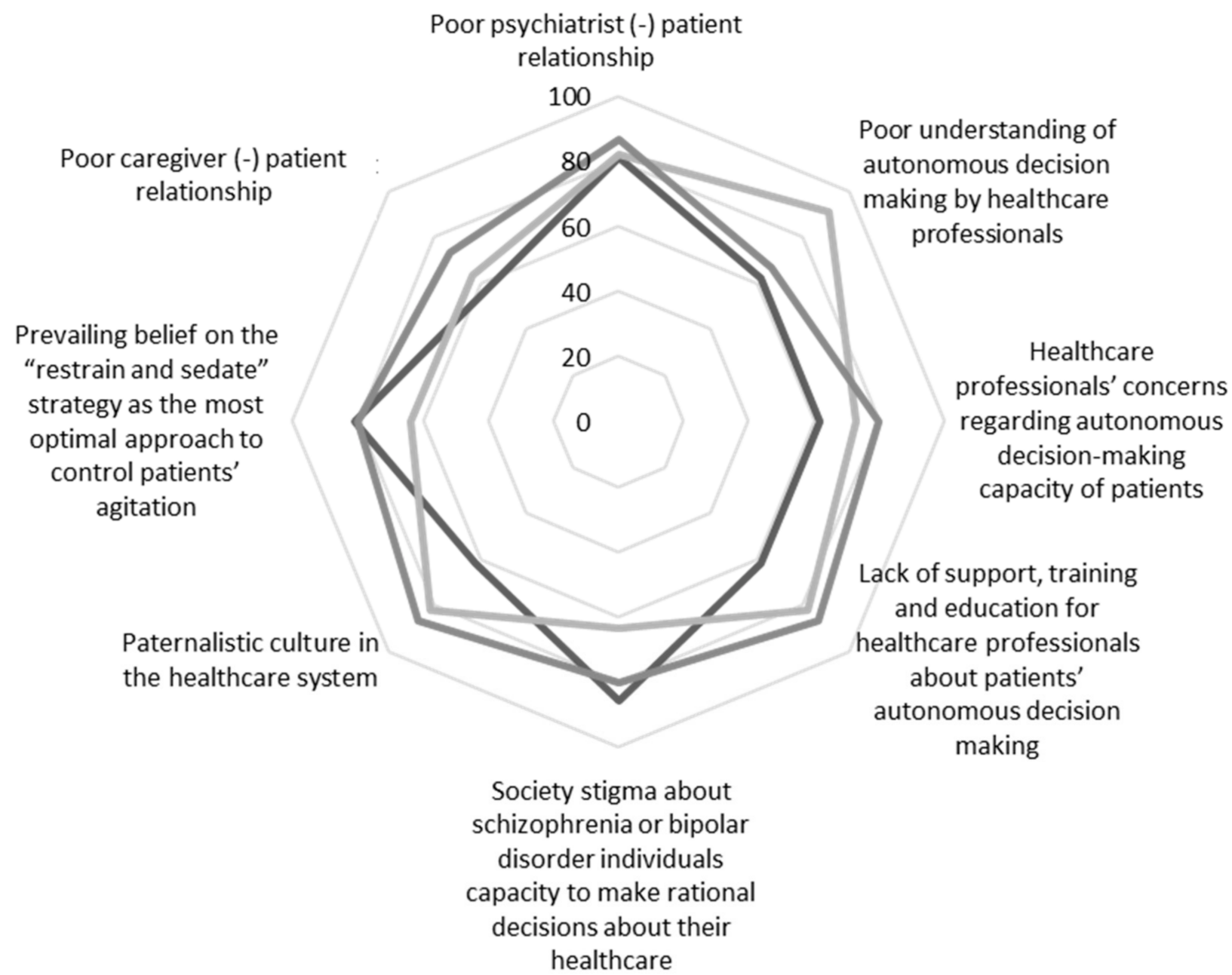

Comparison of the level of importance given to several factors by study participants. The closest to the outside border the tip of the polygon is, the higher percentage of respondents consider that barrier to be "very important" or "most important".

Figure 6. Main barriers to improving illness-related autonomous decision making in individuals with schizophrenia or bipolar disorder. 

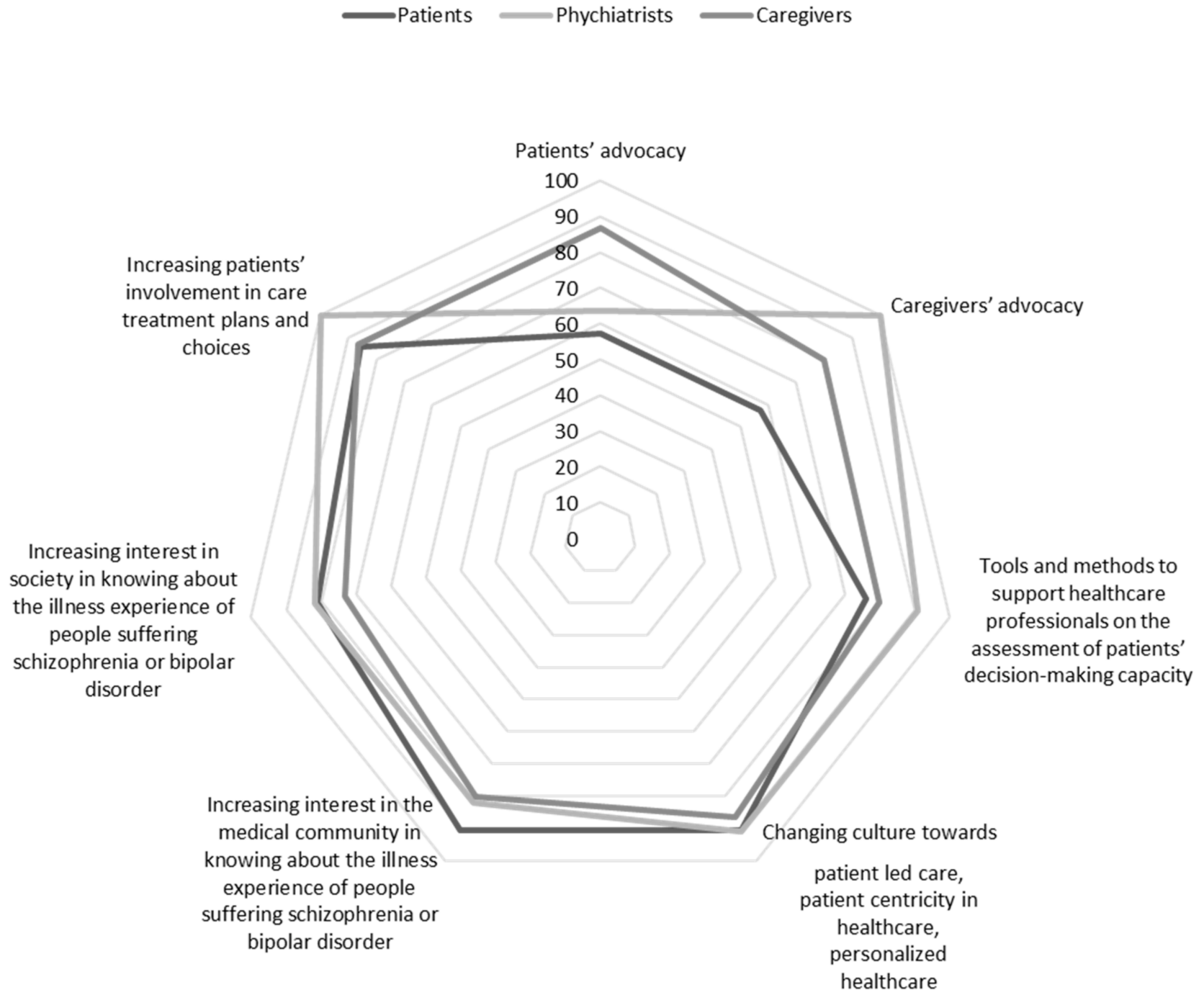

Comparison of the level of importance given to several factors by study participants. The closest to the outside border the tip of the polygon is, the higher percentage of respondents consider that opportunity to be "very important" or "most important".

Figure 7. Main opportunities for improving illness-related autonomous decision making in individuals with schizophrenia or bipolar disorder.

\section{Discussion}

This observational cross-sectional study provides a unique perspective on the views of patients, psychiatrists, and family caregivers on the decisional capacity of individuals with schizophrenia or bipolar disorder on the care of their health, their illness and treatment, crisis anticipation, and future care plans. It describes their perceptions in everyday life in the community, and in this sense, it covers a still under-researched topic. Current evidence on the decisional capacity of severe mental disorder patients addresses their performance while in the hospital or when requiring hospital admission, with little knowledge existing on their healthcare decision-making capacity in everyday life [6]. Similarly, most research conducted on caregivers of persons with schizophrenia or bipolar disorder has focused on the burden of caring, but less is known about caregivers' thoughts about the decisionmaking capacity and desire for decisional engagement of their cared for ones $[19,20]$.

Patients felt frequently involved in discussions and decisions about their healthcare, while the participating psychiatrists considered they often involved their patients in the decisional process. Although it has been reported that psychiatric outpatients often prefer a passive role in the decision-making process compared to their non-psychiatric counterparts 
and that this attitude is stronger in people of older age [21], it has also been pointed out that patients' perceptions of lower-than-preferred involvement may jeopardize shared medical decision making [7]. Culture, personal history, and disease experience are factors among many others that condition the individual desire to actively participate in medical decisions and should be explored in all patient-doctor interactions [22]. Family caregivers were less optimistic about patients having the chance for active involvement. This is in line with previous findings where although more than half of caregivers would prefer a shared decision of the affected person and their healthcare provider, only about one third would remember the last decisions as shared ones, implying that active decisional involvement of patients occurs much more occasionally than expected by relatives [23]. Several methods have been promoted to improve shared decisions in mental healthcare wherein patients are empowered to become more active and self-confident and to acquire greater skills in regard to health literacy and communication, and healthcare providers are trained in analyzing decisional situations and are encouraged to use a wider array of communication strategies to optimize patient participation [24,25]. Further research is needed to learn the reasons behind caregivers' and patients' discrepancy on the level of involvement of patients on healthcare decision making.

The perception of patients with schizophrenia or bipolar disorder active involvement in decisions about planning the future management of crises was low among patients and caregivers alike. Current research shows that advance directives in decision making are an evolving area in mental health as much knowledge, training, and education is still needed among patients, healthcare professionals, and family caregivers [26-28]. It has been reported that many bipolar disorder patients wish to plan care in advance of losing capacity, addressing self-binding issues as well as the request and refusal of treatment [29]. However, practicing advance directives planning in mental health to promote self-determination seems much more erratic than expected by patients and caregivers [30]. Although psychiatrists in this survey were positive about involving patients in healthcare planning, other researches show that most treatment discussion and decision making related to medication across patients with bipolar disorder and schizophrenia refers to stopping, reducing, continuing or changing medication, or deciding on a non-medication alternative, rather than discussing in advance the antipsychotics to be used in a crisis [31].

Overall, all participants in this survey agreed that, in general, schizophrenia and bipolar disorder patients living in the community have the capacity to make decisions about their everyday healthcare and on the pharmacological treatment of their disease. Likewise, other authors have reported that psychiatric patients are capable of making treatment-related decisions, even when being admitted into hospital with considerable burden of symptoms [5,6,32]. In a systematic literature review, Hostiuc et al. (2018) concluded that even in those circumstances in which schizophrenia patients are considered to have a significantly decreased decision-making capacity compared to non-mentally ill patients, they should be considered competent unless very severe changes are identifiable during clinical examination. The authors also argued that the use of enhanced tools to provide enriched information decreases the differences between schizophrenia patients and non-mentally ill individuals and should be used whenever possible and deemed necessary by healthcare professionals [33].

In this survey, participants compared the capacity of patients with schizophrenia or bipolar disorder to make similar decisions about their medical treatment with that of non-psychiatric individuals in similar situations. Evidence shows that compared with diabetes mellitus and Alzheimer's disease individuals, schizophrenia patients of old age perform at an intermediate level in decisional capacity with great heterogeneity among diagnostic groups [34]. According to Sjöstrand et al. (2015), even in severe cases of mental illness, decisional capacity can be retained, and the rate of decision-making incapacity may not be very different among psychiatric inpatients compared to general hospital inpatients in similar circumstances of disease burden [35]. 
Psychiatrists were more coincident with patients than caregivers in their perceptions about the treatment decision-making capacity of individuals with schizophrenia and bipolar disorder, including the anticipation and management of acute psychiatric symptoms, and about the capacity to take the appropriate medications. Previous research has shown that, assuming that adequate support is provided, even patients with an acute psychotic episode who are involuntarily hospitalized and treated may have high treatment decisionmaking capacity [36], and that schizophrenia patients are able to set different clinical and functional goals for the treatment of their illness, including for unexpected situations [37]. Caregivers of persons with schizophrenia or bipolar disorder require further support to preserve their emotional and physical good health and to keep hope for the future alive $[19,20]$. It has been found that currently available policies of support associated with better health and perceptions of the future among caregivers are those that provide them with some leisure time, help them to cope emotionally with caregiving, and give them skills to both enhance their care and to deal with it better [38].

Barriers and opportunities for autonomous decision making among schizophrenia and bipolar disorder patients identified in this survey are coincident with previous findings. Regulations and lack of funding and of effective involvement of society have been suggested as significant barriers, whereas team collaboration, communication skills, training of family caregivers, sound mental healthcare policies, and involvement of the managerial strata in implementation processes have been identified as facilitators [39]. Limited communication about the distressing side effects of pharmacological treatments alongside lack of choice of medication have also been reported as primary sources of concern [40]. The stigma attached to complex mental health conditions experienced by medical staff, patients, and their families represents an overarching obstacle to autonomous decision making among schizophrenia and bipolar disorder patients [41]. Person-centered care in mental health services is a key opportunity to acknowledge mental health patients' capacity to decide on their healthcare issues [42] and to overcome barriers to the empowerment of individuals with a mental illness [43].

Findings in this survey need to be understood in the context of its limitations. The small sample size does not allow us to extrapolate or to claim representativeness of the entire schizophrenia or bipolar disorder population, including physicians and relatives caring for patients. However, this study is exploratory in nature and opens lines for further research. Several other small studies have greatly contributed to the knowledge on the topic of the decision-making capacity of persons with serious mental illnesses [35,44-46]. In future study designs, enough participants should be drawn from countries with similar cultural attitudes to achieve more meaningful results. The questionnaire was developed and distributed in English, which may force a selection bias in favor of participants with a higher level of education and who are more confident and fluent in the use of a foreign language. Most participants resided in non-English speaking countries. Using a questionnaire translated into local languages may have ensured that all participants had equal chances to fully understand each question. The distribution of schizophrenia and bipolar disorder diagnoses among participants may have also shaped differences in responses between groups. Schizophrenia diagnosis was underrepresented among patients and overrepresented among family caregivers. Although the pattern of burden among families of schizophrenia and bipolar disorder individuals is almost identical, the extent of burden among families of schizophrenic patients has been reported to be greater than that of those of bipolar disorder which may shape differences in perceptions of decisional capacity not reflected in this survey [47,48]. Nonetheless, the needs of family caregivers of persons with schizophrenia or bipolar disorder deserve further research.

\section{Conclusions}

In this survey, patients, psychiatrists, and family caregivers were found to agree with the notion that schizophrenia and bipolar disorder individuals have the capacity to make decisions about their everyday healthcare and the pharmacological treatments for their disease, and to discuss benefits and risks of medications, care planning and 
early management of acute symptoms. They also concurred on schizophrenia and bipolar disorder patients' capacity to anticipate acute symptoms and act consequently. Participants assented to the fact that the decisional capacity of schizophrenia and bipolar disorder individuals can be as good as the decisional capacity of patients with other non-psychiatric illnesses in similar circumstances if appropriate support is provided.

Since all stakeholders in this study agree on schizophrenia and bipolar disorder patients' retained capacity to make decisions related to the care of their psychiatric illness in everyday life, encouragement and support for shared decisions among patients, psychiatrists, and family caregivers are needed in order to empower patients to self-care. Therapeutic strategies aligned to the patients' preferred means together with evidence-based information, assessment, and implementation tools should be devised for all stakeholders. In this way, it may be possible to overcome existing barriers and to consolidate the perceived opportunities for autonomy in schizophrenia and bipolar disorder care.

Overall, this exploratory study provides preliminary evidence on the views of patients, psychiatrists, and family caregivers on the capacity for healthcare decision making of patients with schizophrenia and bipolar disorder in everyday life. It lays the groundwork for further exploration of the perceptions of stakeholders that warrant further research.

Author Contributions: Conceptualization: A.C.B., E.V.P., S.P.R., J.H., and M.M.; Formal Analysis: A.C.B., E.V.P., J.H., M.M., and S.P.R.; Funding Acquisition: A.C.B. and E.V.P.; Writing-review and editing: A.C.B., E.V.P., J.H., M.M., and S.P.R.; Writing-original draft: S.P.R. All authors interpreted the data, critically reviewed the intellectual content, and significantly contributed to the writing of the manuscript. All authors agreed on its publication and agreed to be accountable for all aspects of the work to ensure that questions related to the accuracy or integrity of any part of the work would be appropriately investigated and resolved. All authors have read and agreed to the published version of the manuscript.

Funding: Ferrer funded the development of the study and the writing of the manuscript with an unrestricted grant.

Institutional Review Board Statement: Ethical review and approval were waived for this study, due to its exploratory nature based on an anonymous, emailed survey on the views of three different stakeholders.

Informed Consent Statement: Patient consent was waived due to the nature of the study, based on a survey conducted by email and run by patients' and family caregivers' organizations, respectively. Patients received an information sheet providing details about the name of study, objectives, sponsors, data anonymization and processing, and voluntary participation.

Data Availability Statement: The data that support the findings of this study are available from the corresponding author upon reasonable request.

Conflicts of Interest: The authors declare no conflict of interest. The manuscript is an honest, accurate, and transparent account of the study being reported; no important aspects of the study have been omitted; and any discrepancies from the study as planned (and, if relevant, registered) have been explained.

\section{References}

1. Palmer, B.W.; Harmell, A.L. Assessment of Healthcare Decision-making Capacity. Arch. Clin. Neuropsychol. 2016, 31, 530-540. [CrossRef] [PubMed]

2. Stroup, S.; Appelbaum, P.; Swartz, M.; Patel, M.; Davis, S.; Jeste, D.; Kim, S.; Keefe, R.; Manschreck, T.; McEvoy, J.; et al. Decision-making capacity for research participation among individuals in the CATIE schizophrenia trial. Schizophr. Res. 2005, 80, 1-8. [CrossRef] [PubMed]

3. Spencer, B.W.J.; Shields, G.; Gergel, T.; Hotopf, M.; Owen, G.S. Diversity or disarray? A systematic review of decision-making capacity for treatment and research in schizophrenia and other non-affective psychoses. Psychol. Med. 2017, 47, 1906-1922 [CrossRef] [PubMed]

4. Jeste, D.V.; Depp, C.A.; Palmer, B.W. Magnitude of impairment in decisional capacity in people with schizophrenia compared to normal subjects: An overview. Schizophr Bull. 2006, 32, 121-128. [CrossRef] [PubMed] 
5. Pons, E.V.; Salvador-Carulla, L.; Calcedo-Barba, A.; Paz, S.; Messer, T.; Pacciardi, B.; Zeller, S.L. The capacity of schizophrenia and bipolar disorder individuals to make autonomous decisions about pharmacological treatments for their illness in real life: A scoping review. Health Sci. Rep. 2020, 3, e179. [CrossRef] [PubMed]

6. Calcedo-Barba, A.; Fructuoso, A.; Martinez-Raga, J.; Paz, S.; De Carmona, M.S.; Vicens, E. A meta-review of literature reviews assessing the capacity of patients with severe mental disorders to make decisions about their healthcare. BMC Psychiatry 2020, 20, 1-14. [CrossRef]

7. Fisher, A.; Manicavasagar, V.; Sharpe, L.; Laidsaar-Powell, R.; Juraskova, I. A Qualitative Exploration of Clinician Views and Experiences of Treatment Decision-Making in Bipolar II Disorder. Community Ment. Health J. 2017, 53, 958-971. [CrossRef]

8. Jeste, D.V.; Eglit, G.M.L.; Palmer, B.W.; Martinis, J.G.; Blanck, P.; Saks, E.R. Supported Decision Making in Serious Mental Illness. Psychiatry 2018, 81, 28-40. [CrossRef]

9. Wang, S.-B.; Wang, Y.-Y.; Ungvari, G.S.; Ng, C.H.; Wu, R.-R.; Wang, J.; Xiang, Y.-T. The MacArthur Competence Assessment Tools for assessing decision-making capacity in schizophrenia: A meta-analysis. Schizophr. Res. 2017, 183, 56-63. [CrossRef]

10. Matthias, M.S.; Salyers, M.P.; Rollins, A.L.; Frankel, R.M. Decision making in recovery-oriented mental health care. Psychiatr. Rehabilitation J. 2012, 35, 305-314. [CrossRef]

11. Mikesell, L.; Bromley, E.; Young, A.S.; Vona, P.; Zima, B. Integrating Client and Clinician Perspectives on Psychotropic Medication Decisions: Developing a Communication-Centered Epistemic Model of Shared Decision Making for Mental Health Contexts. Health Commun. 2015, 31, 1-11. [CrossRef] [PubMed]

12. Grim, K.; Rosenberg, D.; Svedberg, P.; Schön, U.-K. Shared decision-making in mental health care-A user perspective on decisional needs in community-based services. Int. J. Qual. Stud. Health Well-Being 2016, 11, 30563. [CrossRef] [PubMed]

13. NICE. Decision-Making and Mental Capacity-NICE Guideline. 2018. Available online: https://www.nice.org.uk/guidance/ng1 08/resources/decisionmaking-and-mental-capacity-pdf-66141544670917 (accessed on 20 October 2018).

14. Younas, M.; Bradley, E.; Holmes, N.; Sud, D.; Maidment, I.D. Mental health pharmacists views on shared decision-making for antipsychotics in serious mental illness. Int. J. Clin. Pharm. 2016, 38, 1191-1199. [CrossRef]

15. Gamian-Europe. Global Alliance of Mental Illness Advocacy Networks-Europe [Internet]. 2020. Available online: https: / / www.gamian.eu/ (accessed on 20 April 2020).

16. EUFAMI. European Federation of Families of People Affected by Mental Ill Health-UFAMI [Internet]. 2020. Available online: http:/ / www.eufami.org/ (accessed on 20 April 2020).

17. Garland, R. The mid-point on a rating scale: Is it desirable. Mark Bull. 1991, 2, 66-70.

18. European Commission. Data Protection in the EU [Internet], The General Data Protection Regulation (GDPR), the Data Protection Law Enforcement Directive and Other Rules Concerning the Protection of Personal Data. Available online: https: / / ec.europa.eu/info/law/law-topic/data-protection/data-protection-eu_en (accessed on 6 March 2021).

19. Brain, C.; Kymes, S.; DiBenedetti, D.B.; Brevig, T.; Velligan, D.I. Experiences, attitudes, and perceptions of caregivers of individuals with treatment-resistant schizophrenia: A qualitative study. BMC Psychiatry 2018, 18, 1-13. [CrossRef]

20. Von Kardorff, E.; Soltaninejad, A.; Kamali, M.; Eslami Shahrbabaki, M. Family caregiver burden in mental illnesses: The case of affective disorders and schizophrenia-A qualitative exploratory study. Nord. J. Psychiatry. 2016, 70, 248-254. [CrossRef]

21. Morán-Sánchez, I.; Gómez-Vallés, P.; Bernal-López, M.; Ángeles Pérez-Cárceles, M.D. Shared decision-making in outpatients with mental disorders: Patients' preferences and associated factors. J. Evaluation Clin. Pr. 2019, 25, 1200-1209. [CrossRef]

22. Beitinger, R.; Kissling, W.; Hamann, J. Trends and perspectives of shared decision-making in schizophrenia and related disorders. Curr. Opin. Psychiatry 2014, 27, 222-229. [CrossRef]

23. Liebherz, S.; Tlach, L.; Härter, M.; Dirmaier, J. Information and decision-making needs of psychiatric patients: The perspective of relatives. PeerJ 2017, 5, e3378. [CrossRef]

24. Hamann, J.; Heres, S. Adapting Shared Decision Making for Individuals With Severe Mental Illness. Psychiatr. Serv. 2014, 65, 1483-1486. [CrossRef]

25. Ehrlich, C.; Dannapfel, P. Shared decision making: People with severe mental illness experiences of involvement in the care of their physical health. Ment. Health Prev. 2017, 5, 21-26. [CrossRef]

26. Kemp, K.; Zelle, H.; Bonnie, R.J. Embedding Advance Directives in Routine Care for Persons with Serious Mental Illness: Implementation Challenges. Psychiatr. Serv. 2015, 66, 10-14. [CrossRef] [PubMed]

27. De las Cuevas, C.; Peñate, W.; de Rivera, L. Psychiatric patients' preferences and experiences in clinical decision-making: Examining concordance and correlates of patients' preferences. Patient Educ. Couns. 2014, 96, 222-228. [CrossRef] [PubMed]

28. Gergel, T.; Owen, G.S. Fluctuating capacity and advance decision-making in Bipolar Affective Disorder-Self-binding directives and self-determination. Int. J. Law Psychiatry 2015, 40, 92-101. [CrossRef]

29. Hindley, G.; Stephenson, L.A.; Keene, A.R.; Rifkin, L.; Gergel, T.; Owen, G. "Why have I not been told about this?": A survey of experiences of and attitudes to advance decision-making amongst people with bipolar. Wellcome Open Res. 2019, 4, 16. [CrossRef]

30. Scholten, M.; Gieselmann, A.; Gather, J.; Vollmann, J. Psychiatric Advance Directives Under the Convention on the Rights of Persons With Disabilities: Why Advance Instructions Should Be Able to Override Current Preferences. Front. Psychiatry 2019, 10, 1-13. [CrossRef]

31. Fisher, A.; Manicavasagar, V.; Kiln, F.; Juraskova, I. Communication and decision-making in mental health: A systematic review focusing on Bipolar disorder. Patient Educ. Couns. 2016, 99, 1106-1120. [CrossRef] 
32. Okai, D.; Owen, G.; Mc, H. Mental capacity in psychiatric patients: Systematic review. Br. J. Psychiatry. 2007, 191, 291-297. [CrossRef]

33. Hostiuc, S.; Rusu, M.C.; Negoi, I.; Drima, E. Testing decision-making competency of schizophrenia participants in clinical trials. A meta-analysis and meta-regression. BMC Psychiatry 2018, 18, 2. [CrossRef]

34. Palmer, B.; Dunn, L.; Appelbaum, P.; Al, E. Assessment of capacity to consent to research among older persons with schizophrenia, Alzheimer disease, or diabetes mellitus: Comparison of a 3-item questionnaire with a comprehensive standardized capacity instrument. Arch. Gen. Psychiatry. 2005, 62, 726-733. [CrossRef]

35. Sjöstrand, M.; Karlsson, P.; Sandman, L.; Helgesson, G.; Eriksson, S.; Juth, N. Conceptions of decision-making capacity in psychiatry: Interviews with Swedish psychiatrists Ethics in Public Health, medical law, and health policy. BMC Med Ethics 2015, 16, 1-9. [CrossRef]

36. Mandarelli, G.; Tarsitani, L.; Parmigiani, G.; Polselli, G.M.; Frati, P.; Biondi, M.; Ferracuti, S. Mental Capacity in Patients Involuntarily or Voluntarily Receiving Psychiatric Treatment for an Acute Mental Disorder. J. Forensic Sci. 2014, 59, 1002-1007. [CrossRef]

37. Bridges, J.F.; Kinter, E.T.; Schmeding, A.; Rudolph, I.; Mühlbacher, A. Can Patients Diagnosed with Schizophrenia Complete Choice-Based Conjoint Analysis Tasks? Patient: Patient-Centered Outcomes Res. 2011, 4, 267-275. [CrossRef]

38. Calvó-Perxas, L.; Vilalta-Franch, J.; Litwin, H.; Turro-Garriga, O.; Mira, P.; Garre-Olmo, J. What seems to matter in public policy and the health of informal caregivers? A cross-sectional study in 12 European countries. PLoS ONE 2018, 13, e0194232. [CrossRef]

39. Mariani, E.; Vernooij-Dassen MKoopmans, R.; Engels, Y.; Chattat, R. Shared decision-making in dementia care planning: Barriers and facilitators in two European countries. Aging Ment. Health 2017, 21, 31-39. [CrossRef]

40. Mental Health Commission of New South Wales. Medication and Mental Illness. Perspectives. [Internet]. 2015. Available online: https:/ /nswmentalhealthcommission.com.au/sites/default/files/uploads/Medication \%20and\%20mental\%20illness\% 20perspectives\%20Nov\%202015.pdf (accessed on 20 April 2020).

41. Brophy, L.; Kokanovic, R.; Flore, J.; McSherry, B.; Herrman, H. Community Treatment Orders and Supported Decision-Making. Front. Psychiatry 2019, 10, 1-12. [CrossRef]

42. Gondek, D.; Edbrooke-Childs JVelikonja, T.; Al, E. Facilitators and Barriers to Person-centred Care in Child and Young People Mental Health Services: A Systematic Review. Clin. Psychol. Psychother. 2017, 24, 870-886. [CrossRef]

43. Guidry-Grimes, L. Overcoming Obstacles to Shared Mental Health Decision Making. AMA J. Ethic. 2020, 22 , E446-E451. [CrossRef]

44. Shepherd, A.; Shorthouse, O.; Gask, L. Consultant psychiatrists' experiences of and attitudes towards shared decision making in antipsychotic prescribing, a qualitative study. BMC Psychiatry 2014, 14, 127. [CrossRef] [PubMed]

45. Kikkert, M.J.; Schene, A.H.; Koeter, M.W.J.; Robson, D.; Born, A.; Helm, H.; Nosè, M.; Goss, C.; Thornicroft, G.; Gray, R.J. Medication Adherence in Schizophrenia: Exploring Patients', Carers' and Professionals' Views. Schizophr. Bull. 2005, 32, 786-794. [CrossRef]

46. Lloyd, J.; Lloyd, H.; Fitzpatrick, R.; Peters, M. Treatment outcomes in schizophrenia: Qualitative study of the views of family carers. BMC Psychiatry 2017, 17, 1-10. [CrossRef] [PubMed]

47. Vasudeva, S.; Al, E. Caregivers burden of patients with schizophrenia and bipolar disorder: A sectional study. Indian J. Psychol. Med. 2013, 35, 352-357. [CrossRef] [PubMed]

48. Grover, S.; Chakrabarti, S.; Aggarwal, M.; Avasthi, A.; Kulhara, P.; Sharma, S.; Khehra, N. Comparative study of the experience of caregiving in bipolar affective disorder and schizophrenia. Int. J. Soc. Psychiatry 2011, 58, 614-622. [CrossRef] [PubMed] 